\title{
Internalisation of membrane progesterone receptor- $\alpha$ after treatment with progesterone: Potential involvement of a clathrin-dependent pathway
}

\author{
HELEN FOSTER $^{1}$, ALAN REYNOLDS ${ }^{2}$, GUDRUN STENBECK ${ }^{1}$, JING DONG ${ }^{3}$, \\ PETER THOMAS $^{3}$ and EMMANOUIL KARTERIS ${ }^{1}$ \\ ${ }^{1}$ Centre for Cell Chromosome Biology, Biosciences, School of Health Sciences and Social Care,
and ${ }^{2}$ Experimental Techniques Centre, Brunel University, Uxbridge UB8 3PH, UK;
${ }^{3}$ Marine Science Institute, University of Texas at Austin, Port Aransas, TX 78373, USA
}

Received July 13, 2009; Accepted October 15, 2009

DOI: $10.3892 / \mathrm{mmr} 00000214$

\begin{abstract}
Internalisation and recycling of seven transmembrane domain receptors is a critical regulatory event for their signalling. The mechanism(s) by which membrane progesterone receptor- $\alpha(\mathrm{mPR} \alpha)$ number is regulated on the cell surface is unclear. In this study, we investigated the cellular distribution of $\mathrm{mPR} \alpha$ and mechanisms of $\mathrm{mPR} \alpha$ trafficking using a cell line derived from a primary culture of human myometrial cells (M11) as an experimental model. RT-PCR and immunofluorescent analysis demonstrated expression of $\mathrm{mPR} \alpha$ in M11 cells with $\mathrm{mPR} \alpha$ primarily distributed on the cell surface under basal conditions. For the first time, plasma membrane localisation of $\mathrm{mPR} \alpha$ was confirmed using immunogold transmission electron microscopy. Stimulation of M11 cells with progesterone $(\mathrm{P} 4,100 \mathrm{nM})$ resulted in internalisation of $\mathrm{mPR} \alpha$ from the plasma membrane to the cytoplasm (10 $\mathrm{min}$ ) and subsequent limited translocation back to the cell surface $(20 \mathrm{~min})$. We investigated potential endocytotic pathways involved in trafficking of $m P R \alpha$ after its internalisation. Partial co-localisation of clathrin with $\mathrm{mPR} \alpha$ was obvious after $10 \mathrm{~min}$ of $\mathrm{P} 4$ treatment. Of note, chlorpromazine (inhibitor of clathrin-mediated pathway) inhibited the endocytosis of $\mathrm{mPR} \alpha$, whereas treatment with nystatin (inhibitor of caveolae-mediated pathway) did not affect internalisation. Collectively, these data suggest that $\mathrm{mPR} \alpha$ is expressed on the cell surface of M11 cells and undergoes endocytosis after P4 stimulation primarily via a clathrin-mediated pathway.
\end{abstract}

\section{Introduction}

The large group of seven transmembrane domain receptors (7TMRs) include the well-known superfamily of $\mathrm{G}$ protein

Correspondence to: Dr Emmanouil Karteris, Centre for Cell Chromosome Biology, Biosciences, School of Health Sciences and Social Care, Brunel University, Uxbridge UB8 3PH, UK

E-mail: emmanouil.karteris@brunel.ac.uk

Key words: progesterone, receptors, internalisation, clathrin coupled receptors (GPCRs) as well as the phylogenetically distinct family of membrane progesterone receptors (mPRs) $(1,2)$. Trafficking of 7TMRs between the various cell compartments is crucial for their ligand-binding and signalling functions. Internalisation of 7TMRs by endocytosis controls important receptor functions in the cell, fine tuning the binding characteristics of the receptor and regulating the activation of different signal transduction pathways. Some cell-surface receptors can also activate signal transduction pathways from intracellular compartments, suggesting that signalling can be regulated by compartmentalization (3).

Internalisation of many GPCRs involves rapid clathrinmediated endocytosis (3-5). The agonist-occupied receptor is recruited into clathrin-coated pits (CCP), which then form vesicles for entry into the endocytic pathway. At this stage, vesicles and their cargo can be directed for either degradation or recycling back to the cell surface $(6,7)$. For example, it has been shown that different internalisation routes seem to predetermine whether transforming growth factor $\beta$ (TGF- $\beta$ ) receptors will trigger a signalling response or be degraded (3). The precise mechanisms influencing the fate of the CCPreceptor complex are not fully elucidated, but emerging data suggest that they are receptor specific and may vary between cell types (8). Another route by which GPCRs can be internalised involves caveolae and is independent of clathrin-coated pits $(4,7)$. To date, nothing is known about the internalisation of another family of 7TMRs, the mPRs.

The mPRs were initially discovered in a teleost fish. More than 20 closely related genes have been cloned from other vertebrate species, including $3 \mathrm{mPR}$ subtypes in humans, named $\alpha, \beta$ and $\gamma$, which show high levels of expression in human reproductive, brain and kidney tissues, respectively $(1,2)$. Recently, ligand binding of another two members of the mPR family, named mPR $\delta$ and $\mathrm{mPR} \varepsilon$, has been characterised (9). Structural analyses of the translated cDNAs suggest that they encode membrane proteins with seven transmembrane domains. Thomas et al have shown that $\mathrm{mPR} \alpha$ is a membranebound progestin receptor that activates $G$ proteins, despite having a different ancestral origin to GPCRs (10). Karteris and co-workers have also shown that $\mathrm{mPR} \alpha$ is expressed 
on myometrial cells and couples to inhibitory $G$ proteins, resulting in an increased phosphorylation of myosin light chain (11). However, regulation of $\mathrm{mPR} \alpha$ at the cell surface remains unclear, since there is a debate regarding the cellular distribution of these receptors. Therefore, in the present study we investigated the localisation of $\mathrm{mPR} \alpha$ in M11 cells and potential endocytotic pathways involved in $\mathrm{mPR} \alpha$ trafficking.

\section{Materials and methods}

Tissue culture. M11 cells were obtained from John A. Copland (Mayo Clinic College of Medicine, Jacksonville, FL, USA). These cells were derived from dispersed human myometrial cells by repeated passage without the use of any immortalising or transforming agents. M11 cells were maintained in Dulbecco's modified Eagle's medium (DMEM) high glucose (with D-Valine) supplemented with $10 \%$ fetal bovine serum (FBS), $50 \mathrm{U}$ penicillin and $50 \mu \mathrm{g}$ streptomycin (Invitrogen, $\mathrm{UK}$ ) and cultured at $37^{\circ} \mathrm{C}$ in $5 \% \mathrm{CO}_{2}$.

RNA isolation, $c D N A$ synthesis and RT-PCR. Total RNA was extracted using an RNA extraction kit (Sigma-Aldrich, UK) and treated with DNase I according to the manufacturer's instructions. RNA concentration was determined by spectrophotometric analysis (NanoDrop; Thermo Scientific, UK) and agarose gel electrophoresis. RNA (100 ng) was reverse-transcribed into cDNA using $5 \mathrm{IU} / \mu 1 \mathrm{RNase} \mathrm{H}$ reverse transcriptase (Invitrogen). PCR amplification was carried out using Taq polymerase (Invitrogen) and oligonucleotide primers (Invitrogen) for human $\mathrm{mPR} \alpha$ (Acc. AF313620). The primers for $\mathrm{mPR} \alpha$ were forward 5'-GCTGTTCACTCACATCCC-3' and reverse 5'-TGGTGCAACCCCCAGA-3', resulting in a 289-bp PCR product. The primers for clathrin (138 bp) were forward 5'-TTAGCCGGTGCTGAAGAACT-3' and reverse 5'-CTGGAACCGACGGA TAGTGT-3'. The primers for $\beta$-actin (216 bp) were forward 5'-AAGAGAGGCATCCTCACCCT-3 and reverse 5'-TACATGGCTGGGGTGTTGAA-3'. Thirtythree cycles for $\mathrm{mPR} \alpha$ and 28 cycles for clathrin and $\beta$-actin were performed, consisting of an initial denaturing step at $94^{\circ} \mathrm{C}$ for $30 \mathrm{sec}$ followed by extension at $60^{\circ} \mathrm{C}$ for $1 \mathrm{~min}$ and elongation at $72^{\circ} \mathrm{C}$ for $1 \mathrm{~min}$.

Treatment of M11 cells with progesterone (P4). Prior to P4 treatments, M11 cells were cultured in phenol red-free DMEM containing $2.5 \%$ charcoal-stripped FBS, penicillin and streptomycin, and incubated at $37^{\circ} \mathrm{C}$ in $5 \% \mathrm{CO}_{2}$ for $24 \mathrm{~h}$. Cells were exposed to $100 \mathrm{nM}$ P4 for 0 (NS, unstimulated), 10 and $20 \mathrm{~min}$.

Indirect immunofluorescence analyses using mPR $\alpha$ antibody. M11 cells were fixed in $4 \%$ paraformaldehyde for $10 \mathrm{~min}$ prior to washes in PBS and permeabilization with $0.2 \%$ Tween-20 for $20 \mathrm{~min}$. After subsequent washes in PBS, samples were blocked for $1 \mathrm{~h}$ at room temperature using $10 \%$ bovine serum in PBS. Fixed M11 cells were then incubated with a $1: 100$ dilution of $\mathrm{mPR} \alpha(\mathrm{hmPR} \alpha, 836-4)$ antibody in $1.5 \%$ bovine serum PBS overnight at $4^{\circ} \mathrm{C}$. The following day, preparations were washed with PBS prior to incubation with a 1:100 dilution of anti-rabbit IgG-fluorescein isothiocyanate (FITC)-conjugated antibody (Santa Cruz Biotechnology,
USA) for $1 \mathrm{~h}$. Sample preparations were washed with PBS and mounted in Vectashield ${ }^{\circledR}$ Mounting Medium (Vector labs) containing the DNA-specific dye 4,6-diamido-2-phenylindole (DAPI) to counterstain nuclei. Preparations were incubated with only secondary antibody as a negative control. Images were captured using a Plan Apo Neofluor x63 NA 1.25 oil objective (Zeiss; Carl Zeiss International) on a Zeiss Axiovert 200M microscope, and viewed using AxioVision software (Zeiss; Carl Zeiss International). Images were collected at set exposure times of $3000 \mathrm{msec}$, with the exception of the nuclei counterstained with DAPI, which were collected under an automatic exposure time.

Dual-indirect immunofluorescence using $m P R \alpha$ and clathrin antibodies. The general indirect immunofluorescence protocol described previously was adhered to, with several modifications. Samples were blocked for $1 \mathrm{~h}$ at room temperature in $10 \%$ bovine serum and $10 \%$ donkey serum in PBS. Preparations were incubated at $4^{\circ} \mathrm{C}$ overnight in a 1:100 dilution of $\mathrm{mPR} \alpha$ (hmPR $\alpha, 836-4)$ antibody and a 1:200 dilution of anti-clathrin heavy chain antibody (Abcam, UK) respectively diluted with $1.5 \%$ bovine serum and $1.5 \%$ donkey serum in PBS. The secondary antibody incubation consisted of a 1:100 dilution of anti-rabbit IgG-FITC antibody and a 1:100 dilution of anti-goat IgG rhodamine antibody (both from Santa Cruz Biotechnology, USA) respectively composed with $3 \%$ bovine serum and $3 \%$ donkey serum in PBS for $1 \mathrm{~h}$.

Treatment of M11 cells with endocytosis inhibitors. The dualindirect immunofluorescence protocol described previously using antibodies directed against $\mathrm{mPR} \alpha$ and clathrin was used on M11 cells treated with the following inhibitors for various endocytotic pathways: chlorpromazine, dansylcadverine, nystatin and sucrose. M11 cells were cultured in phenol red-free DMEM containing $2.5 \%$ charcoal-stripped serum, penicillin and streptomycin, and incubated at $37^{\circ} \mathrm{C}$ in $5 \% \mathrm{CO}_{2} 24 \mathrm{~h}$ prior to inhibitor and $\mathrm{P} 4$ treatment. A negative control was prepared in each instance. M11 cells were incubated for $15 \mathrm{~min}$ at $37^{\circ} \mathrm{C}$ with $50 \mu \mathrm{M}$ chlorpromazine hydrochloride (Sigma-Aldrich) using a protocol described previously by Wang et al (12), then assessed under basal conditions (NS) and exposed to $100 \mathrm{nM}$ P4 for $10 \mathrm{~min}$. M11 cells were treated with $25 \mu \mathrm{g} / \mathrm{ml}$ nystatin (Sigma-Aldrich) at $37^{\circ} \mathrm{C}$ for $30 \mathrm{~min}$ as previously described $(13,14)$. Cells were subsequently exposed to $100 \mathrm{nM}$ P4 for $10 \mathrm{~min}$, but also treated under basal conditions (NS). M11 cells were incubated with $0.45 \mathrm{M}$ sucrose (Sigma-Aldrich) at $37^{\circ} \mathrm{C}$ for $15 \mathrm{~min}$, described by Heuser and Anderson at basal conditions and prior to $\mathrm{P} 4$ exposure of $10 \mathrm{~min}$ (15).

Protein extraction from cultured M11 cells. M11 cells were cultured in 6-well dishes until reaching $80 \%$ confluency and maintained overnight in phenol red-free DMEM containing 2.5\% charcoal-stripped FBS, penicillin and streptomycin, before the addition of agonists/inhibitors. Cells were lysed using $200 \mu 12$ X Laemmli Buffer (Sigma-Aldrich) and denatured for $5 \mathrm{~min}$ at $100^{\circ} \mathrm{C}$.

Immunogold electron microscopy. M11 cells were grown to confluency on $35-\mathrm{mm}$ polystyrene dishes at $37^{\circ} \mathrm{C}$ in the presence of $5 \% \mathrm{CO}_{2}$ in high glucose DMEM with $10 \%$ heat- 
A
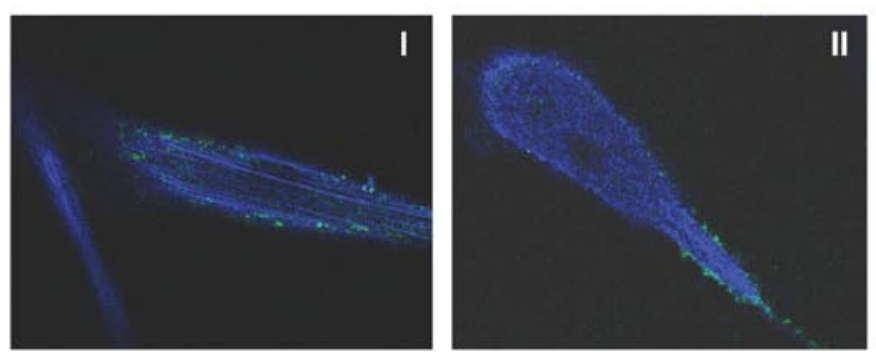

B

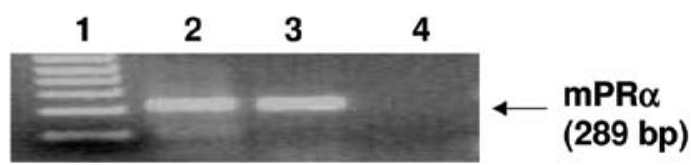

C
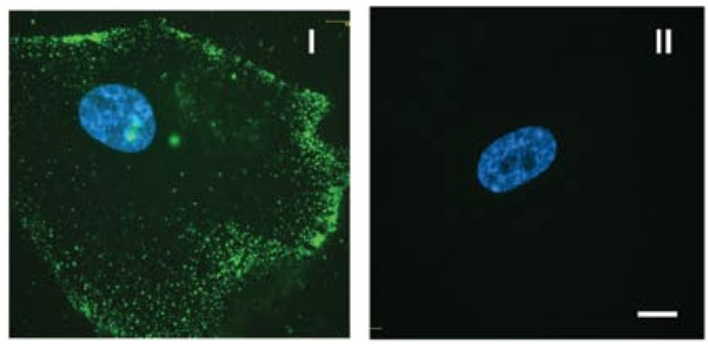

D
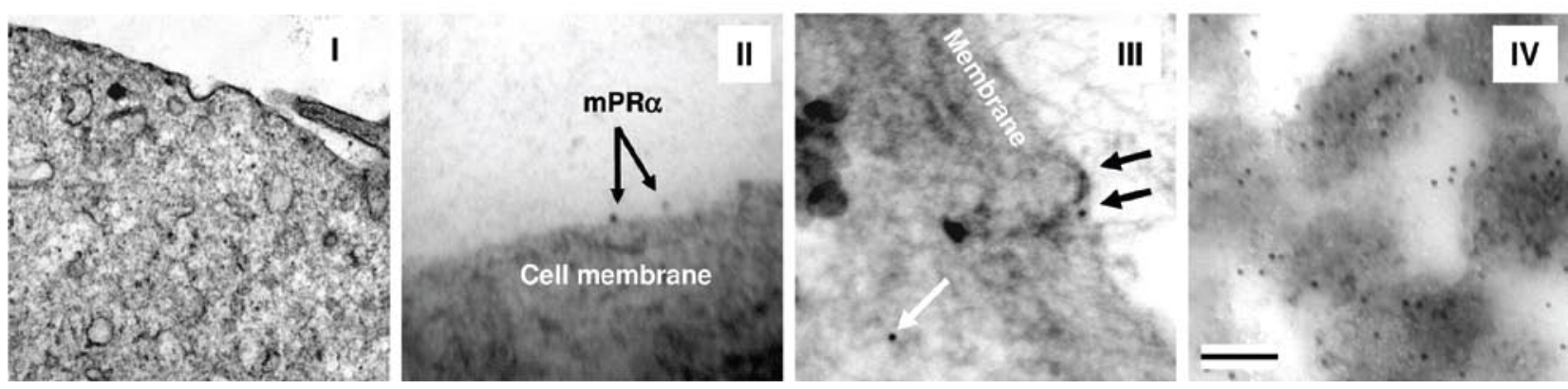

Figure 1. P4 binding, expression and cellular distribution of mPRa in M11 cells. (A) Confocal images of M11 cells incubated with P4 3-(O-carboxymethyl) oxime-BSA-FITC at room temperature for $20 \mathrm{~min}$ (I) and $45 \mathrm{~min}$ (II). Green represents progesterone and blue, phalloidin. (B) RT-PCR analysis for $\mathrm{mPR}$ : Lane 1, DNA ladder; lane 2, cDNA from M11 cells; lane 3, cDNA from myometrial tissue; lane 4, negative control (no cDNA input). (C) Immunofluorescent analysis for $\mathrm{mPR} \alpha$ in an M11 cell showing the distribution of $\mathrm{mPR} \alpha$ (green) across the cell membrane. The nucleus was counterstained with DAPI (blue) (I); II is the negative control. Scale bar, $10 \mu \mathrm{m}$. (D) mPR $\alpha$ localisation and the cellular morphology of M11 cells using TEM. M11 cells had intact cytoplasmic machinery and a distinct cell membrane (I). Immunogold electron microscopy revealed mPR $\alpha$ localisation and distribution detected via a secondary antibody conjugated to 10-nm gold beads. This revealed specific staining on the cell membrane (indicated by black arrows, II and III) and within the cytoplasm (indicated by white arrow, III). IV is a control preparation depicting the size of the 10-nm gold beads conjugated to the anti-rabbit secondary antibody used in these preparations. Scale bar, $100 \mathrm{~nm}$, with the exception of I, $250 \mathrm{~nm}$

inactivated FBS, penicillin and streptomycin. Cells were washed with $0.1 \mathrm{M}$ Sorensen's phosphate buffer $(\mathrm{pH}$ 7.0) and fixed in $0.1 \%$ glutaraldehyde for $30 \mathrm{~min}$ at room temperature. Cells were washed and then blocked with $10 \%$ donkey serum for $30 \mathrm{~min}$ at room temperature. Anti-clathrin antibody (Sigma-Aldrich) diluted 1:40 with Sorensen's phosphate buffer containing $1 \%$ donkey serum and $0.1 \%$ sodium azide was applied to the cells and incubated overnight at $4^{\circ} \mathrm{C}$. Washed cells were incubated in 18-nm gold labelled donkey anti-goat IgG secondary antibody, $1 \%$ donkey serum and $0.1 \%$ sodium azide for $1 \mathrm{~h}$ at room temperature. Post-fixation was performed in $2 \%$ glutaraldehyde for $10 \mathrm{~min}$ followed by fixation with $1 \%$ osmium tetroxide for $1 \mathrm{~h}$ at room temperature. The cells were dehydrated through a graded ethanol series and embedded in epoxy resin. Ultrathin sections were collected on copper grids and stained with uranyl acetate and lead citrate prior to observation by transmission electron microscopy (EM) using a JEOL 2000 FX Transmission Electron Microscope.

M11 cells were also probed with $\mathrm{mPR} \alpha(\mathrm{hmPR} \alpha, 836-4)$ antibody and goat anti-rabbit IgG 10-nm gold labelled secondary antibody. These cells were treated using the aforementioned protocol with the following exceptions: firstly, cells were blocked in $1 \%$ bovine serum albunin (BSA), $10 \%$ goat serum; secondly, antibodies were diluted in $1 \%$ goat serum, $1 \%$ BSA and $0.1 \%$ sodium azide made up in $0.1 \mathrm{M}$ Sorensen's phosphate buffer $\mathrm{pH}$ 7.0.

P4 binding. M11 cells incubated in Opti-MEM (Invitrogen) supplemented with $30 \mathrm{mM}$ HEPES and $0.2 \%$ BSA were grown on glass bottomed Petri dishes. These were incubated with $100 \mathrm{nM}$ progesterone 3-(O-carboxymethyl)oxime: BSA-fluorescein isothiocynate conjugate (Sigma-Aldrich) for 10 and $45 \mathrm{~min}$ at room temperature prior to fixation with 4\% paraformaldehyde for $10 \mathrm{~min}$. After subsequent washes with PBS, the cells were permeabilised with $0.1 \%$ saponin, $0.5 \%$ BSA in PBS for 20 min. Fixed cells were then washed with PBS and incubated with a 1:300 dilution of phalloidinAlexa fluor 568 (Molecular probes, UK) in 0.5\% BSA PBS for 15 min prior to further PBS washes. The M11 cells were mounted with antifade solution (Citifluor-PBS, Citifluor Ltd., UK) and visualised using a Nikon Eclipse TE2000S confocal microscope. 

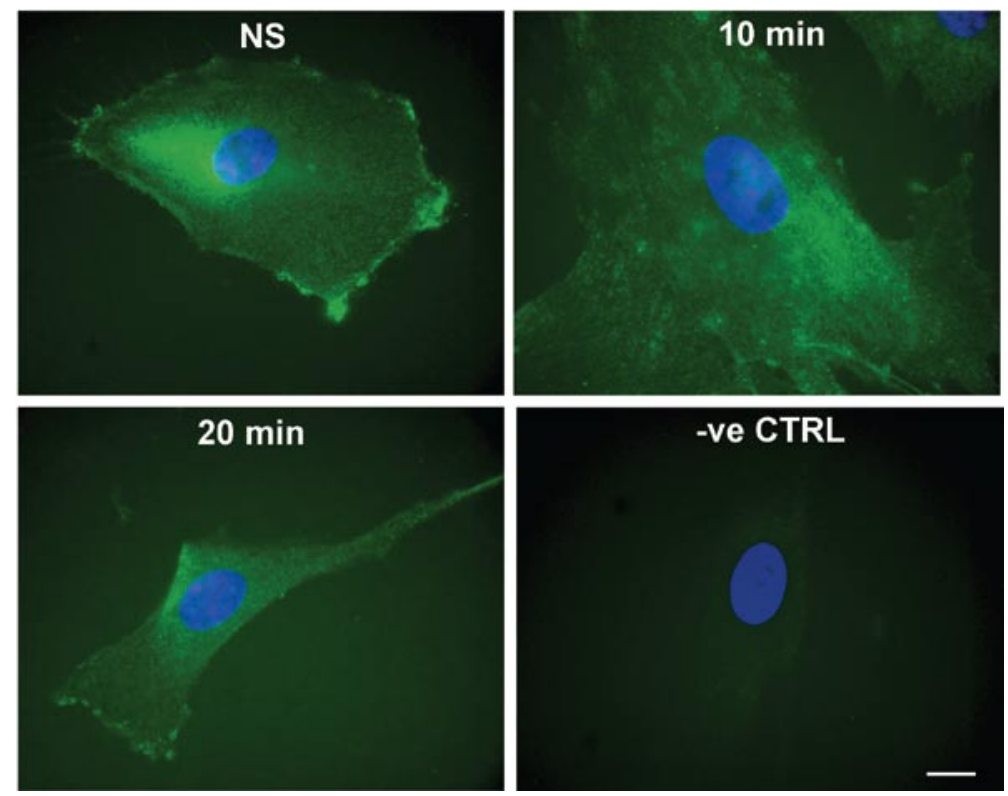

Figure 2. Distribution of $\mathrm{mPR} \alpha$ in M11 cells upon stimulation with P4. Under basal conditions (NS), mPR $\alpha$ was predominantly confined to the cell surface. After 10 min of treatment with $100 \mathrm{nM} \mathrm{P4}$, translocation of $\mathrm{mPR} \alpha$ from the cell surface towards the cytoplasm was evident. However, after exposure to P4 for 20 min, a substantial amount of $\mathrm{mPR} \alpha$ protein was localised back at the plasma membrane. Scale bar, $10 \mu \mathrm{m}$. -ve CTRL, negative control immunostaining with secondary antibody only.

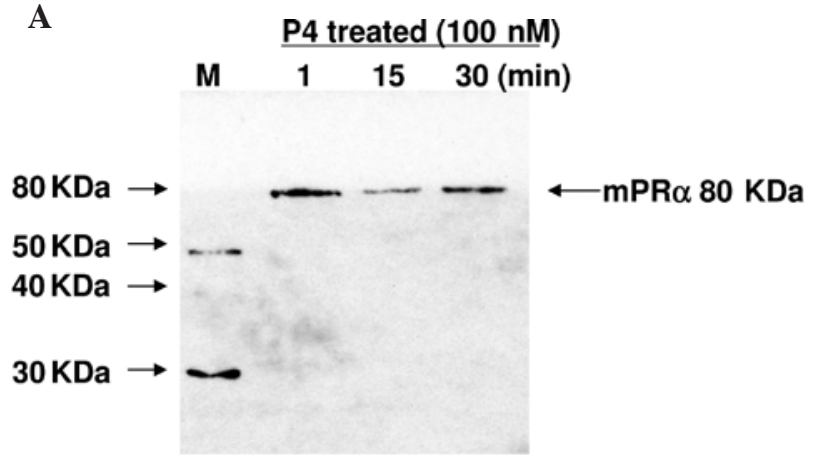

B
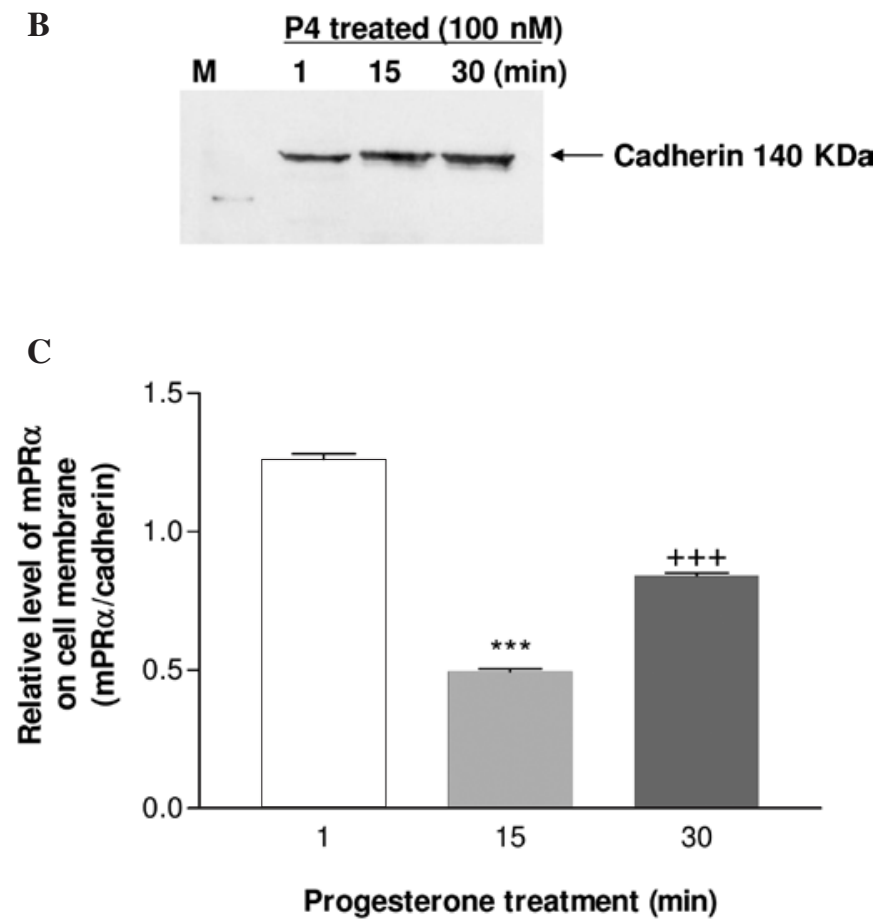

Statistical analysis. Expression mPR $\alpha$ protein was determined using Western blot analysis as described previously (11) and with semi-quantitative densitometry performed using $\mathrm{NIH}$ ImageJ (v1.26).

\section{Results}

Membrane binding of progesterone, expression and cellular distribution of $m P R \alpha$ in M11 cells. Membrane progesterone sites were detected in M11 cells upon incubation with P4 3-(O-carboxymethyl)oxime-BSA-FITC at room temperature for $20 \mathrm{~min}$ (Fig. 1A, panel I) and $45 \mathrm{~min}$ (Fig. 1A, panel II).

Expression of $\mathrm{mPR} \alpha$ at the gene level was confirmed in M11 cells via RT-PCR (Fig. 1B). Furthermore, mPR $\alpha$ expression was verified at the protein level through indirect immunofluorescence (Fig. 1C) and immunogold electron microscopy (Fig. 1D), both of which depict characteristic plasma membrane localisation in M11 cells under basal conditions.

Electron microscopy is the gold standard and the most robust technique for determining the cellular distribution of $\mathrm{mPR} \alpha$ within M11 cells. Using this technique, we verified that M11 cells have an intracellular environment rich in the mandatory organelles essential for transcription and translation processes (Fig. 1D, panel I). Immunogold EM provided

Figure 3. Western blot analysis of $\mathrm{mPR} \alpha$ protein M11 plasma membranes after exposure to P4 for a 1-, 15- and 30-min duration. (A) M11 plasma membrane preparations (P4 $100 \mathrm{nM}$ for 1,15 and $30 \mathrm{~min}$ ) probed with an $\mathrm{mPR} \alpha$ antibody resulting in $80 \mathrm{kDa}$ bands. (B) Immunoblotting with a cadherin antibody shows equal membrane protein loading on the gel for each time point. (C) Semi-quantification of $\mathrm{mPR} \alpha$ protein on M11 plasma membrane samples by the normalisation of $\mathrm{mPR} \alpha$ protein with cadherin protein and semi-quantitative densitometry performed using NIH ImageJ (v1.26). Statistical differences were determined for each of the different $\mathrm{P} 4$ exposure times $\left({ }^{* * *} \mathrm{P}<0.001\right.$ compared with $1 \mathrm{~min} ;{ }^{++} \mathrm{P}<0.001$ compared with 1 and $15 \mathrm{~min}$; one way ANOVA). 
A

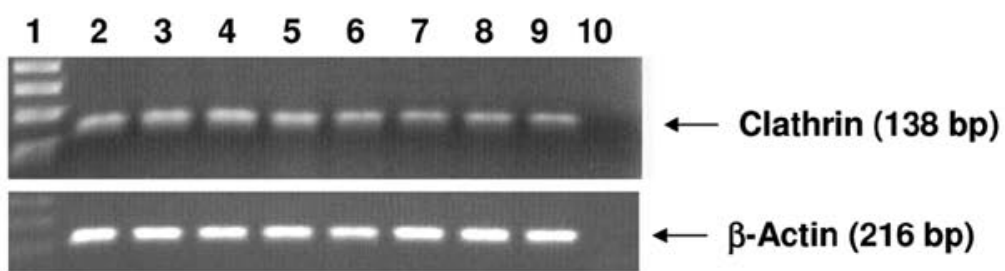

B
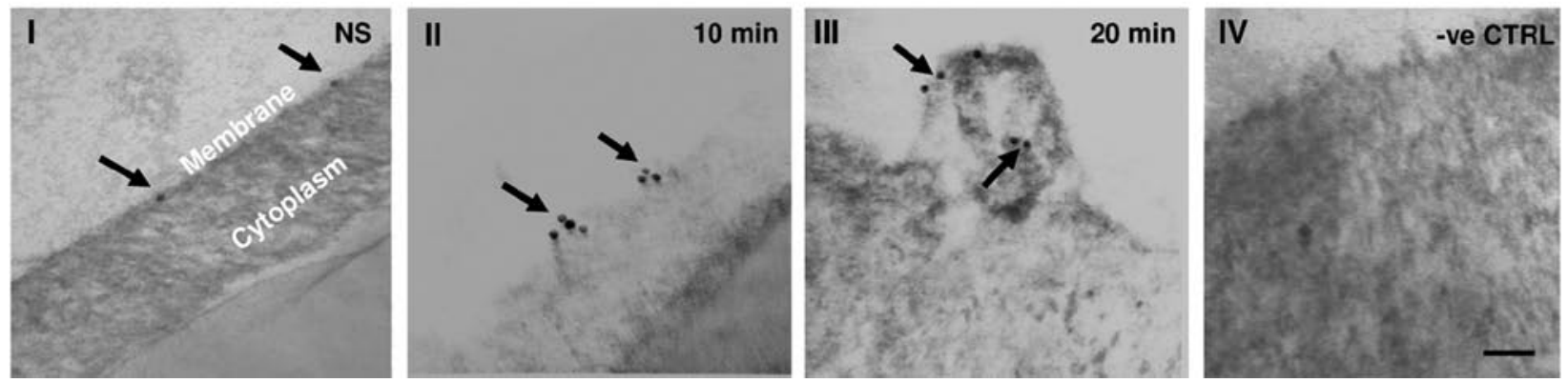

Figure 4. Expression of clathrin in M11 cells and its cellular distribution. (A) RT-PCR analysis for clathrin and $\beta$-actin in P4-treated M11 samples. Lane 1, DNA ladder; lane 2, NS; lanes 3-9, cDNA from M11 cells treated with P4 for 1, 3, 5, 10, 15, 20 and 30 min respectively; lane 10, negative control. (B) Immunogold electron microscopy illustrating the localisation and distribution of clathrin in M11 cells detected via a secondary antibody conjugated to 18 nm gold beads. This revealed clathrin (arrows) to be dispersed in non-P4-treated M11 cells (I). After exposure to P4 for 10 min, clathrin appeared to form clusters (II). At 20 min of P4 treatment, clathrin was present both on the cell membrane and internalised within the cytoplasm (III). IV, negative control. Scale bar, $100 \mathrm{~nm}$.

irrefutable evidence for the first time that $\mathrm{mPR} \alpha$ occupies a location at the cell membrane in M11 cells under basal conditions (Fig. 1D, panel II). Nevertheless, mPR $\alpha$ also occasionally occupied an intracellular locality within the cell cytoplasm (Fig. 1D, panel III).

Sequestration and trafficking of $m P R \alpha$ from the plasma membrane after P4 stimulation. To study the potential trafficking of $\mathrm{mPR} \alpha$ and to further determine its distribution pattern, immunofluorescent analyses were conducted in M11 cells treated with P4 (100 nM) for 5, 10 and $20 \mathrm{~min}$. In untreated cells, $\mathrm{mPR} \alpha$ was localised both at the cell surface and cytoplasm (Fig. 2; NS). Following 5 min of P4 treatment, there was an altered distribution of the receptor with $\mathrm{mPR} \alpha$ present both on the cell membrane and in the cytoplasm (data not shown). At $10 \mathrm{~min}$ of treatment, there was a clear decline in $\mathrm{mPR} \alpha$ localised to the cell membrane (Fig. 2; $10 \mathrm{~min}$ ), whereas at $20 \mathrm{~min}$ the receptor was again detected on the plasma membrane (Fig. 2; $20 \mathrm{~min}$ ).

To confirm trafficking of $\mathrm{mPR} \alpha$ following progesterone treatment, solubilised M11 plasma membrane preparations treated with $100 \mathrm{nM}$ P4 for 1, 15 and $30 \mathrm{~min}$ (Fig. 3A) were subjected to Western blot analysis with $\mathrm{mPR} \alpha$ specific antibodies. Plasma membrane levels of $\mathrm{mPR} \alpha$ protein varied with the duration of $\mathrm{P} 4$ exposure. The highest level of $\mathrm{mPR} \alpha$ protein was present at the membrane after a 1-min exposure to $\mathrm{P} 4$, with a subsequent reduction in levels at 15 min of treatment and an increase at $30 \mathrm{~min}$. Western blot analysis using an antibody directed against cadherin (Fig. 3B), a transmembrane protein involved in cell adhesion, was used as a control to normalise $\mathrm{mPR} \alpha$ protein levels in the plasma membrane (Fig. 3B). Normalised $\mathrm{mPR} \alpha /$ cadherin levels showed a significant dif- ference $(\mathrm{P}<0.001)$ when comparing protein from the $15-\mathrm{min}$ $\mathrm{P} 4$ exposure to the 1-min exposure, with a reduction in $\mathrm{mPR} \alpha$ present at the plasma membrane at $15 \mathrm{~min}$. A significant difference $(\mathrm{P}<0.001)$ in $\mathrm{mPR} \alpha$ protein levels also occurred when comparing the 30-min P4 exposure to the 1- and 15-min P4 exposures, with 30-min P4 levels being statistically lower than the 1-min levels, but higher than the 15-min levels (Fig. 3C). These data support the hypothesis that $\mathrm{mPR} \alpha$ is expressed on the cell membrane, rapidly internalised after stimulation with $\mathrm{P} 4$, and then recycled/shuttled back to the plasma membrane.

Expression and distribution of clathrin in M11 cells. As mentioned previously, a major mechanism for the internalisation of GPCRs is via clathrin-mediated endocytosis. Therefore, in order to investigate the potential involvement of clathrin in the endocytosis of $\mathrm{mPR} \alpha$, we characterised its expression and trafficking in M11 cells. Semi-quantitative RT-PCR analysis revealed that, firstly, clathrin mRNA is expressed in M11 cells, and, secondly, that its expression remains unaltered with up to $30 \mathrm{~min}$ of $\mathrm{P} 4$ treatment (Fig. 4A). Immunogold EM was also used to reveal that there are distinct changes in the distribution of clathrin in P4-stimulated M11 cells. After 10 min of P4 treatment, there was a change in clathrin distribution, with a noticeable increase in cluster sequestration (Fig. 4B, panel II; 10 min compared to panel I; NS). At 20 min of P4 treatment, there was a distinct internalisation of clathrin in the cytoplasm, with some remaining on the plasma membrane (Fig. 4B, panel III; $20 \mathrm{~min}$ ).

Co-distribution of $m P R \alpha$ with clathrin. Under basal conditions, clathrin was distributed throughout the cell (Fig. 5A; NS), whereas mPR $\alpha$ was predominantly limited to the plasma membrane. Little colocalisation between clathrin and $\mathrm{mPR} \alpha$ 

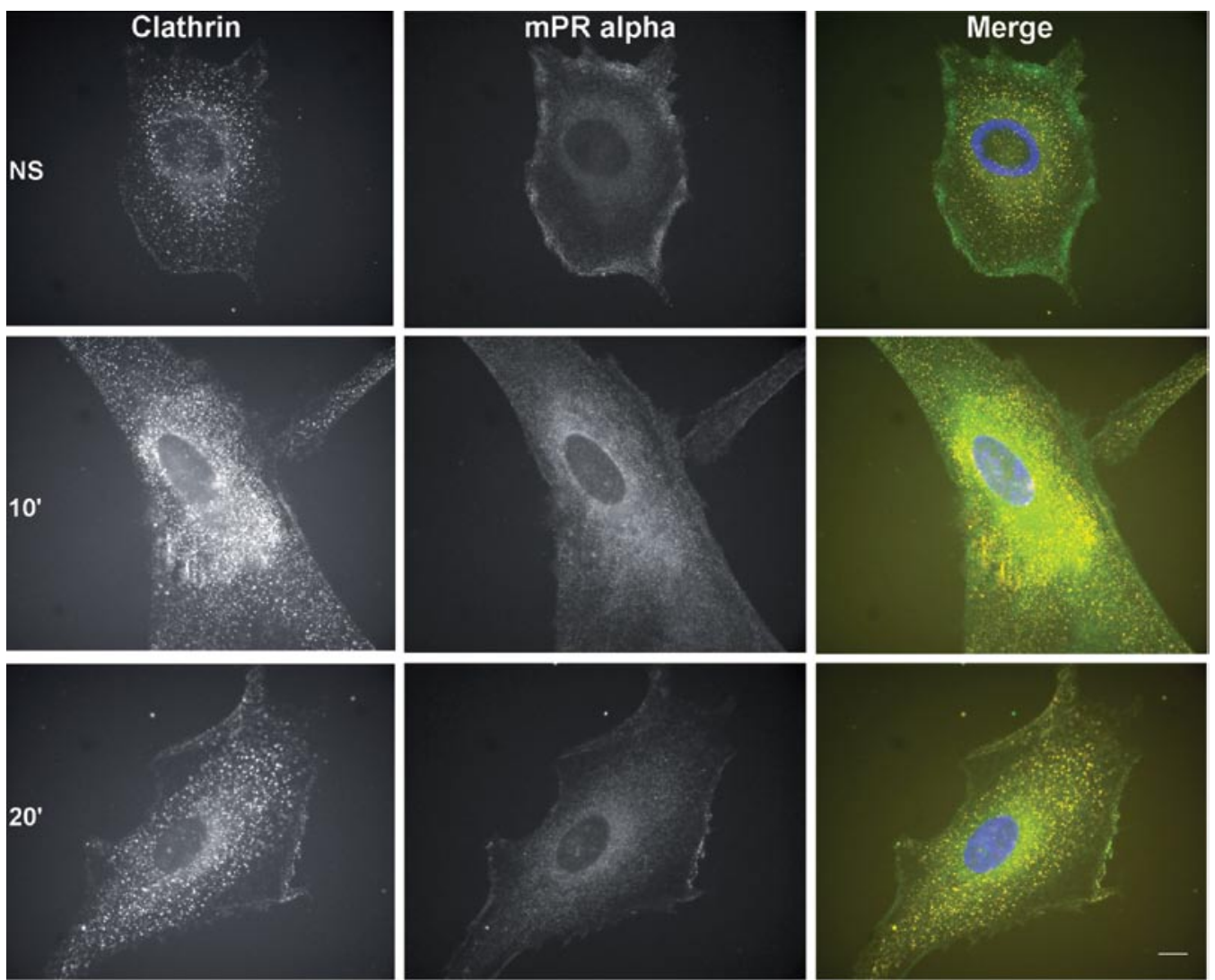

Figure 5. Colocalisation of $\mathrm{mPR} \alpha$ and clathrin in P4-treated M11 cells. The immunofluorescent images depict the distribution and partial colocalisation of $\mathrm{mPR} \alpha$ (green) and clathrin (orange) in M11 cells. Nuclei were counterstained with DAPI (blue). Clathrin and mPR $\alpha$ colocalisation was determined in M11 cells after treatment with P4 for 10 and $20 \mathrm{~min}$. Scale bar, $10 \mu \mathrm{M}$.
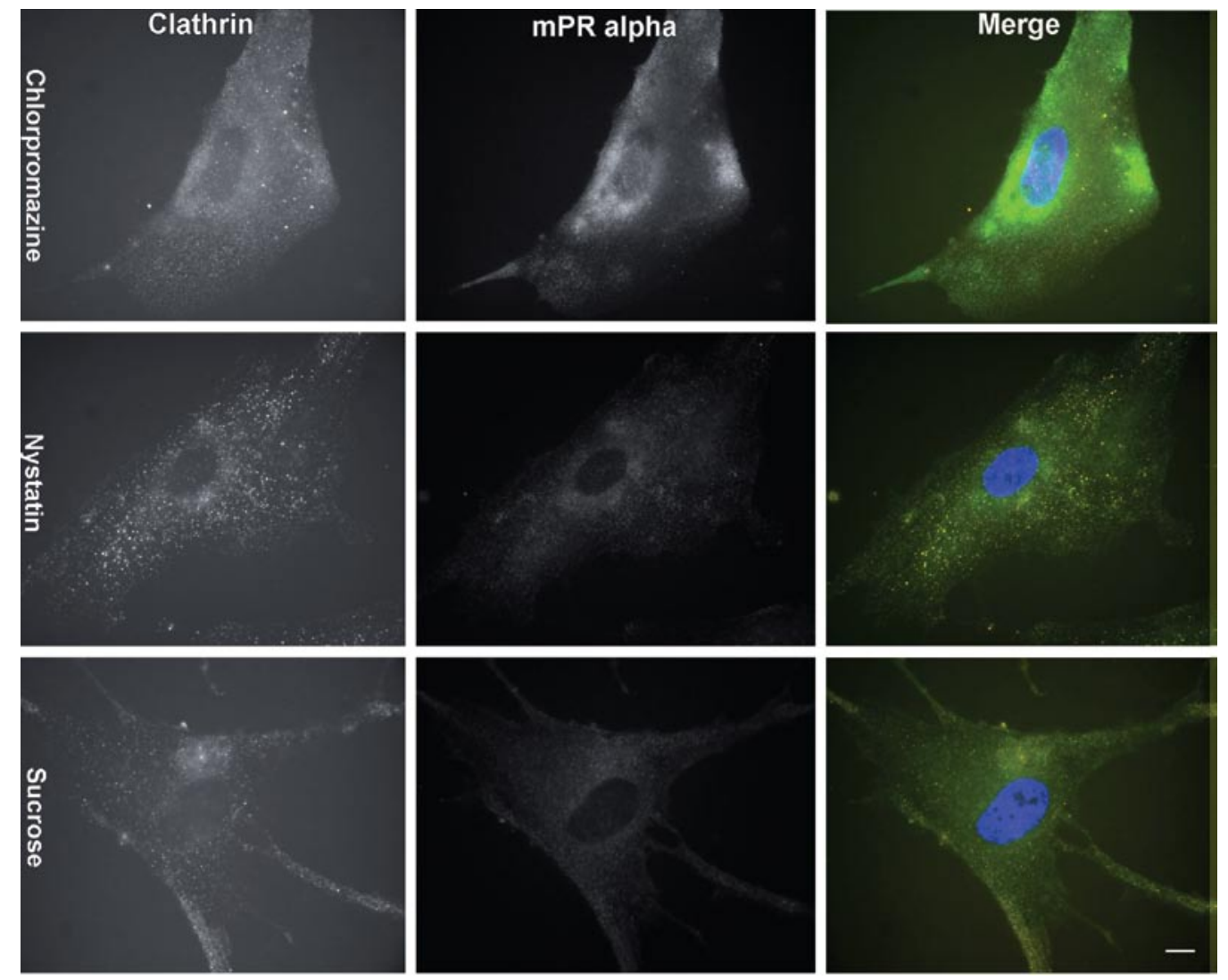

Figure 6. Effect of inhibitors on clathrin and mPRa endocytosis in M11 cells. M11 cells were exposed to P4 for 10 min prior to treatment with specific inhibitors to determine how this influences clathrin and $\mathrm{mPR} \alpha$ endocytosis. The immunofluorescent images depict clathrin (orange) and $\mathrm{mPR} \alpha$ (green) treated with chlorpromazine, nystatin or sucrose. Scale bar, $10 \mu \mathrm{M}$. 
was evident (Fig. 5A; NS). At 10 min of P4 exposure, both clathrin and $\mathrm{mPR} \alpha$ were increasingly localised within the cell (Fig. 5A; $10 \mathrm{~min}$ ). Partial colocalisation between mPR $\alpha$ and clathrin was determined, visible in the merged image as orange-coloured speckles (Fig. 5A; $10 \mathrm{~min}$ ). The distribution of both mPR $\alpha$ and clathrin at 20 min of P4 treatment seemingly reverted to that observed under basal conditions (Fig. 5A; $20 \mathrm{~min})$.

Use of endocytotic inhibitors to investigate potential internalisation pathways of $m P R \alpha$. At $10 \mathrm{~min}$ of $\mathrm{P} 4$ exposure, internalisation and partial colocalisation of $\mathrm{mPR} \alpha$ and clathrin was evident in the M11 cells (Fig. 5A; $10 \mathrm{~min}$ ). Inhibitors of endocytosis were used on M11 cells, which were then exposed to $10 \mathrm{~min}$ of $\mathrm{P} 4$ treatment to examine the resultant distribution and colocalisation properties of clathrin and $m P R \alpha$. Treatment of M11 cells with chlorpromazine resulted in an atypical clathrin distribution, with a reduction in observed clathrin speckles (Fig. 6; chlorpromazine). $\mathrm{mPR} \alpha$ appeared to be sequestered in much larger, but fewer, clusters localised at either the cell membrane or the cellular interior (Fig. 6; chlorpromazine). No clear colocalisation between clathrin and $\mathrm{mPR} \alpha$ was apparent (Fig. 6; chlorpromazine). Nystatin inhibitor did not alter the clathrin or $\mathrm{mPR} \alpha$ distribution, nor their partial colocalisation, which is readily observed under standard conditions (Fig. 6; nystatin). Sucrose treatment of M11 cells altered mPR $\alpha$ distribution (Fig. 6; sucrose). The internal clustering of mPR $\alpha$ typically seen in M11 cells was also less apparent, with no observable internal sequestration of mPR $\alpha$ (Fig. 6; sucrose). Clathrin and $\mathrm{mPR} \alpha$ did not appear to colocalise when treated with sucrose.

\section{Discussion}

In this study, we investigated the cellular distribution and trafficking of $m P R \alpha$ in a human myometrial cell line (M11). We chose this experimental model since it has been shown to have morphological characteristics typical of myometrial cells (16), and also expresses mPR $\alpha(11,17)$.

Immunofluorescent analysis revealed that $\operatorname{mPR} \alpha$ has a similar subcellular distribution to that previously observed in human myometrial cells under basal conditions (11), and is localised on the plasma membrane, with some cytoplasmic expression. In agreement with these results, membrane localisation of mPRs has been demonstrated by several research groups in a variety of cell types $(1,10,18-22)$. Other researchers have reported mPRs to be localised intracellularlly in the endoplasmic reticulum (23-25). EM is the gold standard in high resolution imaging, and was used to conclusively determine the sub-cellular distribution of mPR $\alpha$. mPR $\alpha$ occupies a cell membrane location under basal conditions, but intracellular mPR $\alpha$ is also apparent. These novel data incorporated EM for the first time to address $\mathrm{mPR} \alpha$ distribution in any given cell type.

An important characteristic of 7TMRs is that they are rapidly internalised upon activation in a ligand-dependent manner, an event critical for their proper functioning (26). Currently, there is no information on the trafficking of $\mathrm{mPR} \alpha$. Therefore, we utilised an immunofluorescent approach to investigate the trafficking of $\mathrm{mPR} \alpha . \mathrm{mPR} \alpha$ protein was redistributed from the cell membrane in unstimulated cells, becoming internalised at $10 \mathrm{~min}$ of $\mathrm{P} 4$ exposure. $\mathrm{mPR} \alpha$ was presented back on the cell membrane at $20 \mathrm{~min}$, but not to the levels previously seen under basal conditions. This was ligand specific, since treatment with the unrelated steroid cortisol $(100 \mathrm{nM})$ and the nuclear PR activator R5020 (30 nM) did not induce any significant internalisation of the receptor in M11 cells (data not shown). The $\mathrm{mPR} \alpha$ internalisation was confirmed by specific single-point P4 binding studies. At $20 \mathrm{~min}$, there was a significant decrease in $\left[{ }^{3} \mathrm{H}\right]-\mathrm{P} 4$ binding on the plasma membrane of M11 cells as compared with 1-min P4 treatment (data not shown). The decrease in membrane-bound $\mathrm{mPR} \alpha$ may act as a desensitisation process to modulate rapid P4 signalling responses.

These data are consistent with the data in the literature, which indicate that the intracellular segregation of receptors due to endocytotic events is a common fate for 7TMRs. This provides another explanation for why several 7TMRs appear to be expressed in the cytoplasm (27), and may also explain why some investigators have observed mPRs intracellularly. In kidney tissue, $\mathrm{mPR} \alpha$ was found to be restricted to the endoplasmic reticulum (ER) due to a C-terminal ER retention motif (25). This is not unusual for 7TMRs, since many require accessory proteins to ensure transport to the plasma membrane $(28,29)$. An example is the melanocortin 2 receptor, which is localised within the ER and cannot be transported to the plasma membrane unless it is co-expressed with the melanocortin 2 receptor accessory protein (28). It possible, therefore, that $\mathrm{mPR} \alpha$ requires an accessory protein that is expressed in tissue- or cell-specific manner, thus affecting its transport to the membrane. These studies highlight the difficulty in drawing any firm conclusions on 7TMR trafficking (30), and present an arguement for a higher order of complexity regarding $\mathrm{mPR} \alpha$ distribution.

The next step of this study was to further dissect the endocytotic pathway(s) involved in $\mathrm{mPR} \alpha$ trafficking. Endocytosis of activated receptors can be mediated via caveolae/lipid raft mechanisms (32) and clathrin-dependent endocytosis. Lipid rafts are sterol- and sphingolipid-rich membrane domains comprising caveolae subdomains involved in the endocytosis of various ligands $(32,33)$. However, for most 7TMRs, endocytosis is implemented via clathrin-mediated mechanisms involving the formation of coated pits at the cell surface that concentrate surface protein/cargo for internalisation (34).

The role of clathrin in the endocytosis of $\mathrm{mPR} \alpha$ in M11 cells was investigated. Following progesterone treatment, there was partial co-localisation of clathrin with $\mathrm{mPR} \alpha$, evident in Fig. 5 as orange speckles. In addition, co-immunoprecipitation studies show that clathrin is immunoprecipitated with $\mathrm{mPR} \alpha$, indicating a close association between these two proteins and suggesting that they may be coupled under certain conditions (data not shown). M11 cells were treated with various inhibitors of endocytosis prior to progesterone treatment. Inhibitors were chosen according to their ability to discriminate and inhibit different types of endocytotic pathways. Treatments included chlorpromazine and sucrose inhibitors specific for clathrinmediated internalisation and nystatin, which inhibits caveolae/ lipid-raft mediated endocytosis $(35,36)$. These inhibitors do not demonstrate absolute selectivity between endocytotic pathways; nevertheless, they are commonly used to differentiate trafficking routes (37). Chlorpromazine inhibitor acts by preventing the adapter protein AP2 from binding to clathrin- 
coated pits $(12,38)$, whereas sucrose inhibitor acts by interfering with clathrin recruitment, coated pit formation and endocytosis (39). These inhibitors prevented the clathrin-mediated endocytosis of $m P R \alpha$. Nystatin is a polyene antibiotic that inhibits caveolae/lipid raft-mediated endocytosis by the sequestration of cholesterol within the membrane, but does not affect clathrin-mediated endocytosis. Nystatin pre-treatment did not alter the internalisation of $\mathrm{mPR} \alpha$ after $10 \mathrm{~min}$ of $\mathrm{P} 4$ exposure. Collectively, these data do not support a role for caveolae in the mediation of $\mathrm{mPR} \alpha$ endocytosis. In line with these observations, 7TMRs have been found to predominantly use the clathrin-dependent endocytotic pathway, whereas caveolin and clathrin/caveolin-independent pathways appear to be used to a lesser extent $(8,40,41)$. Interestingly, other uncharacterised endocytotic pathways may be involved in receptor trafficking. For instance, corticotropin-releasing hormone receptors appear to undergo endocy tosis independent of clathrin or caveolin upon activation by urocortin (42). It is therefore possible that $\mathrm{mPR} \alpha$ is also capable of internalising via another route, independent of clathrin or caveolin.

Potential changes in the phosphorylation status of the receptor may also affect its trafficking dynamics. There are two different types of kinases that can phosphorylate GPCRs: i) second-messenger-dependent kinases (e.g., PKC), and ii) GPCR kinases (GRKs). $\beta$-arrestins have an essential role following receptor phosphorylation, functioning as adaptor molecules that link receptors to clathrin-coated pits (43-45). Potential phosphorylation sites of $\mathrm{mPR} \alpha$ were predicted using the NetPhosK Server. mPR $\alpha$ can be phosphorylated at two serine sites (positions 219, 229), three threonine sites (positions 32, 57 and 232) and three tyrosine sites (positions 143, 194 and 304). Future studies, using mutational analysis of these sites, will provide better insight regarding the potential role of $\mathrm{mPR} \alpha$ phosphorylation in endocytotic events.

In summary, these data provide the first definitive evidence that $\mathrm{mPR} \alpha$ can be localised on the plasma membrane and within the cytoplasm. This is particularly important given that receptor number on the cell surface is a fine balance between the rate of internalisation, recycling and new synthesis, and the fact that many receptors may also signal from endosomal compartments (3). Potential mechanisms involved in P4-mediated endocytosis have also been investigated, providing novel insight on mPR-mediated responses. Future studies should focus on determining $\mathrm{mPR} \alpha$ degradation, recycling to the cell surface and activation of distinct intracellular pathways while internalised.

\section{Acknowledgements}

The authors thank John A. Copland for the kind gift of M11 cells. This research was funded by a National Institutes of Health Grant ESO ESO12961 to P.T. and E.K. We would also like to thank Dr David Ribé for the assistance in confocal microscopy.

\section{References}

1. Zhu Y, Bond J and Thomas P: Identification, classification and partial characterization of genes in humans and other vertebrates homologous to a fish membrane progestin receptor. Proc Natl Acad Sci USA 100: 2237-2242, 2003.
2. Zhu Y, Rice CD, Pang Y, Pace M and Thomas P: Cloning, expression and characterization of a membrane progestin receptor and evidence it is an intermediary in meiotic maturation of fish oocytes. Proc Natl Acad Sci USA 100: 2231-2236, 2003.

3. Felberbaum-Corti M, van der Goot FG and Gruenberg J: Sliding doors: clathrin-coated pits or caveolae? Nat Cell Biol 5: 382-384, 2003.

4. Mueller A, Kelly E and Strange PG: Pathways for internalization and recycling of the chemokine receptor CCR5. Blood 99: 785-791, 2002.

5. Koenig JA and Edwardson JM: Endocytosis and recycling of G protein-coupled receptors. Trends Pharmacol Sci 18: 276-287, 1997.

6. Von Zastrow M: Mechanisms regulating membrane trafficking of $\mathrm{G}$ protein-coupled receptors in the endocytic pathway. Life Sci 74: 217-274, 2003.

7. Le Roy C and Wrana JL: Clathrin- and non-clathrin-mediated endocytic regulation of cell signalling. Nat Rev Mol Cell Biol 6: 112-126, 2005.

8. Grampp T, Sauter K, Markovic B and Benke D: Gammaaminobutyric acid type B receptors are constitutively internalized via the clathrin-dependent pathway and targeted to lysosomes for degradation. J Biol Chem 282: 24157-24165, 2007.

9. Smith JL, Kupchak BR, Garitaonandia I, Hoang LK, Maina AS, Regalla LM and Lyons TJ: Heterologous expression of human $\mathrm{mPR} \alpha, \mathrm{mPR} \beta$ and $\mathrm{mPR} \gamma$ in yeast confirms their ability to function as membrane progesterone receptors. Steroids 73: 1160-1173, 2008.

10. Thomas P, Pang Y, Dong J, Groenen P, Kelder J, De Vlieg J, Zhu Y and Tubbs C: Steroid and G protein binding characteristics of the seatrout and human progestin membrane receptor-alpha subtypes and their evolutionary origins. Endocrinology 148: 705-718, 2007.

11. Karteris E, Zervou S, Pang Y, Dong J, Hillhouse EW, Randeva HS and Thomas P: Progesterone signalling in human myometrium through two novel membrane $G$ protein-coupled receptors: potential role in functional progesterone withdrawal at term. Mol Endocrinol 20: 1519-1534, 2006.

12. Wang LH, Rothberg KG and Anderson RG: Mis-assembly of clathrin lattices on endosomes reveals a regulatory switch for coated pit formation. J Cell Biol 123: 1107-1117, 1993.

13. Hartung A, Bitton-Worms $\mathrm{K}$, Rechtman MM, Wenzel V, Boergermann JH, Hassel S, Henis YI and Knaus P: Different routes of bone morphogenic protein (BMP) receptor endocytosis influence BMP signalling. Mol Cell Biol 26: 7791-7805, 2006.

14. Idkowiak-Baldys J, Becker KP, Kitatani K and Hannun YA: Dynamic sequestration of the recycling compartment by classical protein kinase C. J Biol Chem 281: 22321-2233, 2006.

15. Heuser JE and Anderson RG: Hypertonic media inhibit receptormediated endocytosis by blocking clathrin-coated pit formation. J Cell Biol 108: 389-400, 1989.

16. Devost D and Zingg HH: Novel in vitro system for functional assessment of oxytocin action. Am J Physiol Endocrinol Metab 292: 1-6, 2007.

17. Fernandes MS, Pierron V, Michalovich D, Astle S, Thornton S, Peltoketo H, Låam EW, Gellersen B, Huhtaniemi I, Allen J and Brosens JJ: Regulated expression of putative membrane progestin receptor homologues in human endometrium and gestational tissues. J Endocrinol 187: 89-101, 2005.

18. Dosiou C, Hamilton AE, Pang Y, Overgaard MT, Tulac S, Dong J, Thomas P and Guidice LC: Expression of membrane progesterone receptors (mPRs) on human T lymphocytes and Jurkat cells and activation of $\mathrm{G}$ proteins by progesterone. J Endocrinol 196: 67-77, 2008.

19. Hanna R, Pang Y, Thomas P and Zhu Y: Cell surface expression, progestin binding and rapid nongenomic signaling of zebrafish membrane progestin receptors $\alpha$ and $\beta$ in transfected cells. J Endocrinol 190: 247-260, 2006.

20. Ben-Yehoshua LF, Lewellyn AL, Thomas P and Maller JL: The role of Xenopus membrane progesterone receptor $\beta$ in mediating the effect of progesterone on oocyte maturation. Mol Endocrinol 21: 664-673, 2007.

21. Nutu $\mathrm{M}$, Weijdegård $\mathrm{B}$, Thomas $\mathrm{P}$, Bergh $\mathrm{C}$, Thurin-Kjellberg $\mathrm{A}$, Pang Y, Billig $\mathrm{H}$ and Larsson DG: Membrane progesterone receptor-gamma: tissue distribution and expression in ciliated cells in the fallopian tube. Mol Reprod Dev 74: 843-850, 2007.

22. Tubbs $\mathrm{C}$ and Thomas P: Progestin signaling through an olfactory $\mathrm{G}$ protein and membrane progestin receptor-alpha in Atlantic croaker sperm: potential role in induction of sperm hypermotility. Endocrinology 150: 473-484, 2009. 
23. Krietsch T, Fernandes MS, Kero J, Lösel R, Heyens M, Lam EW, Huhtaniemi I, Brosens JJ and Gellersen B: Human homologs of the putative $\mathrm{G}$ protein-coupled membrane progestin receptors $(\mathrm{mPR} \alpha, \beta$ and $\gamma$ ) localize to the endoplasmic reticulum and are not activated by progesterone. Mol Endocrinol 20: 3146-3164, 2006.

24. Ashley RL, Clay CM, Farmerie TA, Niswender GD and Nett TM Cloning and characterization of an ovine intracellular seven transmembrane receptor for progesterone that mediates calcium mobilization. Endocrinology 147: 4151-4159, 2006

25. Lemale J, Bloch-Faure M, Grimont A, El Abida B, Imbert-Teboul M and Crambert G: Membrane progestin receptors alpha and gamma in renal epithelium. Biochim Biophys Acta 1783: 2234-2240, 2008.

26. Moore CA, Milano SK and Benovic JL: Regulation of receptor trafficking by GRKs and arrestins. Annu Rev Physiol 69: 451-482, 2007.

27. Thompson MD, Burnham WM and Cole DE: The G proteincoupled receptors: pharmacogenetics and disease. Crit Rev Clin Lab Sci 42: 311-392, 2005.

28. Cooray SN, Almiro do Vale I, Leung KY, Webb TR, Chapple JP, Egertová M, Cheetham ME, Elphick MR and Clark AJ: The melanocortin 2 receptor accessory protein exists as a homodimer and is essential for the function of the melanocortin 2 receptor in the mouse y1 cell line. Endocrinology 149: 1935-1941, 2008.

29. Cooray SN, Chan L, Metherell L, Storr H and Clark AJ: Adrenocorticotropin resistance syndromes. Endocr Dev 13: 99-116, 2008.

30. Gellersen B, Fernandes MS and Brosens JJ: Non-genomic progesterone actions in female reproduction. Hum Reprod Update 15: 119-138, 2009.

31. Thomas P: Characteristics of membrane progestin receptor alpha $(\mathrm{mPR} \alpha)$ and progesterone membrane receptor component one (PGMRC1) and their roles inmediating rapid progestin actions. Front Neuroendocrinol 29: 292-312, 2008.

32. Nabi IR and Le PU: Caveolae/raft-dependent endocytosis. J Cell Biol 161: 673-677, 2003.

33. Lajoie P and Nabi IR: Regulation of raft-dependent endocytosis. J Cell Mol Med 11: 644-653, 2007.

34. Mousavi SA, Malerød L, Berg T and Kjeken R: Clathrin-dependent endocytosis. Biochem J 377: 1-16, 2004.

35. Grewal JS, Luttrell LM and Raymond JR: G protein-coupled receptors desensitize and down-regulate epidermal growth factor receptors in renal mesangial cells. J Biol Chem 276: 27335-27344, 2001.
36. Rakhit S, Pyne S and Pyne NJ: Nerve growth factor stimulation of p42/p44 mitogen-activated protein kinase in PC12 cells: role of $\mathrm{G}(\mathrm{i} / \mathrm{o}), \mathrm{G}$ protein-coupled receptor kinase 2, beta-arrestin I and endocytic processing. Mol Pharmacol 60: 63-70, 2001.

37. Tulapurkar ME, Schäfer R, Hanck T, Flores RV, Weisman GA, González FA and Reiser G: Endocytosis mechanism of P2Y2 nucleotide receptor tagged with green fluorescent protein: clathrin and actin cytoskeleton dependence. Cell Mol Life Sci 62: 1388-1399, 2005

38. Kanerva A, Raki M, Ranki T, Särkioja M, Koponen J, Desmond RA, Helin A, Stenman UH, Isoniemi H, Höckerstedt K, Ristimäki A and Hemminki A: Chlorpromazine and apigenin reduce adenovirus replication and decrease replication associated toxicity. Gene Med 9: 3-9, 2007.

39. Smith J, Yu R and Hinkle PM: Activation of MAPK by TRH requires clathrin-dependent endocytosis and PKC but not receptor interaction with beta-arrestin or receptor endocytosis. Mol Endocrinol 15: 1539-1548, 2001.

40. Ferguson SS: Evolving concepts in G protein-coupled receptor endocytosis: the role in receptor desensitization and signaling. Pharmacol Rev 53: 1-24, 2001.

41. Marchese A, Chen C, Kim YM and Benovic JL: The ins and outs of $\mathrm{G}$ protein-coupled receptor trafficking. Trends Biochem Sci 28: 369-376, 2003.

42. Tu H, Kastin AJ and Pan W: Corticotropin-releasing hormone receptor (CRHR)1 and CRHR2 are both trafficking and signaling receptors for urocortin. Mol Endocrinol 21: 700-711, 2007.

43. Ferguson SS, Downey WE III, Colapietro AM, Barak LS, Ménard L and Caron MG: Role of beta-arrestin in mediating agonist-promoted $\mathrm{G}$ protein-coupled receptor internalization. Science 27: 363-366, 1996.

44. Lefkowitz RJ and Shenoy SK: Transduction of receptor signals by beta-arrestins. Science 308: 512-517, 2005.

45. Pierce KL and Lefkowitz RJ: Classical and new roles of betaarrestins in the regulation of G-protein-coupled receptors. Nat Rev Neurosci 2: 727-733, 2001.

46. Felberbaum-Corti $M$ and Gruenberg J: Signaling from the far side. Mol Cell 10: 1259-1260, 2002. 